\title{
PENGARUH HEDONIC MOTIVATION, SOCIAL INFLUENCE, DAN PERCEIVED ENJOYMENT TERHADAP PENGGUNAAN MARKETPLACE PADA UMKM DI BALI: STUDI KASUS PADA HIPMI PROVINSI BALI
}

\author{
${ }^{a}$ Gusi Putu Lestara Permana, b A.A. Ayu Indah Parasari \\ ${ }^{a, b}$ Fakultas Ekonomi dan Bisnis, Universitas Pendidikan Nasional (Undiknas) Denpasar \\ alestarapermana@undiknas.ac.id, bindahparasari961@gmail.com
}

\begin{abstract}
The purpose of this research is 1) To find out the positive influence of Hedonic Motivation on the Use of Marketplace in UMKM registered in the Hipmi Province of Bali. 2) To find out the positive influence of social influence on the use of the marketplace in UMKM registered in the Hipmi Province of Bali. 3) To find out the positive influence of Perceived Enjoyment on the Use of Marketplace in UMKM registered in Hipmi Province of Bali. The technique of collecting data using a questionnaire. The sample in this study were 100 people who belonged to the active member of Hipmi Bali Province with a purposive sampling method. Data were analyzed using regression analysis techniques, descriptive statistics, determination, $F$ test, and test with the help of SPSS for Windows software. The results of the study found that 1) Hedonic Motivation had a positive and significant effect on marketplace use in UMKM. 2) Social Influence has a positive and significant effect on marketplace use in UMKM. 3) Perceived Enjoyment has a positive and significant effect on marketplace use in UMKM.
\end{abstract}

Keywords: hedonic motivation, social influence, perceived enjoyment, umkm, marketplace

\section{PENDAHULUAN}

Sektor usaha mikro, kecil, dan menengah (UMKM) di Indonesia dinilai mempunyai potensi yang sangat besar. Bahkan setidaknya tercatat 88,8 persen UMKM memberi kontribusi ekonomi di ASEAN. Tidak hanya di Indonesia, salah satu pusat pergerakan sektor ekonomi di Bali juga Usaha Mikro Kecil Menengah (UMKM). UMKM juga menjadi salah satu faktor penting dalam upaya menggerakkan roda perekonomian, dan meningkatkan pendapatan daerah. Dengan produktifnya UMKM di suatu daerah, tentu akan berimplikasi kepada tersedianya lapangan pekerjaan baru yang dan mampu mengikis jumlah pengangguran, serta pemerataan pembangunan dan hasil - hasil khususnya di bidang ekonomi dan peningkatan Pendapatan Domestik Regional Bruto. Tingkat pertumbuhan sektor UMKM di Bali tumbuh rata-rata 5,6 persen pada triwulan I tahun 2017 dibandingkan periode yang sama pada tahun 2016. Angka ini lebih tinggi dari rata-rata nasional yang hanya mencapai 2,44 persen. Bidang-bidang usaha yang mengalami pertumbuhan cukup tinggi misalnya pada biang kuliner, kerajinan, tekstil dan layanan wisata lainnya.

Dengan berkembang pesatnya perkembangan UMKM di Bali, maka persaingan dalam dunia bisnis juga semakin ketat. Di tengahnya arus globalisasi membuat UMKM harus memutar otak untuk menciptkan inovasi baru, baik dari segi produk maupun jasa sehingga memungkinkan para pelaku UMKM mampu bertahan dalam dunia bisnis. Perkembangan UMKM saat ini dibarengi dengan kemajuan di bidang teknologi, komputer, dan telekomunikasi yang turut serta mendukung perkembangan teknologi internet. Internet dapat dimanfaatkan dalam segala bidang, untuk bidang pendidikan, pemerintah, perbankan, penyuluhan kepada masyarakat, kesehatan, dan untuk dunia bisnis / UMKM.

Dalam dunia UMKM internet dapat mempermudah akses penjualan karna internet merupakan sebuah jaringan yang mempunyai cakupan yang sangat luas dan tidak terbatas. Segala aktivitas yang berhubungan dengan segala kebutuhan, mulai dari kebutuhan usaha, 
rumah tangga, kebutuhan pribadi dll. Semua bisa di akses lewat internet, sehingga dengan memanfaatkan sebuah jaringan internet, para pelaku UMKM mencoba untuk memperluas jaringan usaha mereka ke segala sektor yang lebih luas agar dapat bersaing dalam dunia usaha, memudahkan komunikasi dari luar daerah sehingga tidak dihalangi oleh jarak, waktu, dan tempat untuk berkomunikasi bisa melalui skype/media sosial lainnya, lebih hemat waktu dan lebih mudah bertransaksi (fleksibel).

Internet merupakan sebuah jaringan yang sangat fleksibel, semua orang dapat mengakses internet kapanpun dan dimanapun. Maka dengan ini, internet bisa memudahkan bagi para konsumen untuk melakukan sebuah transaksi pembelian tanpa harus datang ke tempat distributor/penjual untuk membeli produk yang dibutuhkan, dan dapat melakukan pemesanan/pembelian sebuah produk kapanpun dan dimanapun. Ini merupakan peluang untuk memiliki pelanggan lebih banyak dari berbagai daerah. Selain itu, dengan adanya internet mempermudah mendapatkan informasi, sehingga para pelaku UMKM bisa memberikan berbagai macam informasi bagi para konsumen dan klien, baik informasi seputar perusahaan ataupun seputar produk yang dimiliki. Dengan pemanfaatan dan penggunaan teknologi internet diharapkan dapat memberikan manfaat yang besar terhadap dunia bisnis yang kompetitif tersebut. Perusahaan yang mampu bersaing dalam kompetisi tersebut adalah perusahaan yang mampu mengimplementasikan teknologi dan informasi kedalam perusahaannya. Salah satu jenis implementasi teknologi dalam hal meningkatkan persaingan bisnis dan penjualan produk-produk adalah dengan menggunakan Electronic Commerce (ecommerce).

Electronic commerce (e-commerce) merupakan konsep yang bisa digambarkan sebagai proses jual beli barang pada internet atau proses jual beli atau pertukaran produk, jasa, dan informasi melalui jaringan informasi termasuk internet. Penggunaan e-commerce sebagai sarana pemasaran produk UMKM melalui website dan marketplace. Marketplace merupakan bagian dari E-Commerce, Marketplace biasanya mempunyai sistem tersendiri yang dapat mengatur ratusan bahkan jutaan produk yang ingin dijual maupun di beli. Marketplace adalah sebuah lokasi jual beli produk dimana seller dan juga konsumen bertemu di suatu tempat. Seller akan menjual barangnya di lapak yang sudah disediakan oleh $e-$ commerce dengan konsep marketplace. Barang yang dijual di marketplace tersebut kemudian akan diiklankan oleh pihak e-commerce untuk mendapatkan konsumen yang potensial. Salah satu faktor kesuksesan e-commerce dengan konsep marketplace ini ditentukan oleh banyaknya jumlah seller dan juga konsumen yang bergabung di website e-commercet ersebut. Pada dasarnya konsep e-commerce dengan menggunakan cara ini hanyalah persoalan pengiklanan. Konsep jual belinya mirip dengan konsep di pasar tradisional. Pasar akan semakin terkenal jika ia memiliki banyak penjual dan banyak pembeli. Semakin banyak penjual maka akan semakin lengkap produk yang dijual sehingga semakin banyak pembeli yang datang.

Nilai perdagangan online di Indonesia tahun 2015 sebesar US\$1,1 miliar. Ini yang terbesar di kawasan ASEAN, melampaui Singapura dan Thailand. Namun, penetrasi perdagangan secara online di Indonesia sebenarnya masih rendah. Euromonitor mencatat, nilai transaksi US\$1,1 miliar itu hanya 0,7 persen dari total nilai perdagangan retail di Indonesia. Sementara itu, penetrasi e-commerce di dua raksasa ekonomi dunia, yaitu Cina dan Amerika Serikat masing-masing 10,6 persen dan 8,3 persen. Bila dibandingkan dengan kawasan ASEAN pun, penetrasi pasar e-commerce di Indonesia juga kalah dibandingkan tiga negara lainnya, yaitu Malaysia, Thailand dan Singapura yang masing-masing 0,9 persen; 1,2 persen; dan 3,4 persen (https://www.katadata.co.id/, n.d.). Hal ini cukup memprihantikan di era globalisasi seperti ini pemerintah sangat menyayangkan jika UMKM ini tidak menggunakan marketplace dalam melakukan aktifitas jual beli. Pasalnya jika UMKM ini menggunakan marketplace maka secara tidak langsung Indonesia dapat menguasai pasar. Pemerintah sendiri akan mengupayakan melalui berbagai cara untuk dapat membantu para pelaku UMKM agar dapat menggunakan marketplace dalam melakukan aktifitas jual beli. Pemerintah juga mengharapkan agar para pelaku UMKM dapat memanfaatkan platform digital ini. Sehingga yang menjadi keinginan pemerintah agar di tahun 2020 minimal UMKM 
yang menggunakan marketplace dalam melakukan aktifitas jual beli sebanyak 5 sampai 8 juta UMKM dapat tercapai.

Salah satu organisasi yang bergerak dalam bidang kewirausahaan adalah HIPMI. HIPMI adalah singkatan dari Himpunan Pengusaha Muda Indonesia. HIPMI merupakan organisasi independen non partisan. HIPMI bukan merupakan underbouw dari organisasi manapun. HIPMI didirikan pada tanggal 10 Juni 1972. HIPMI telah sukses mencetak kaderisasi wirausaha, dengan tampilnya tokoh-tokoh muda dalam percaturan dunia usaha nasional maupun internasional. Keadaan itu kemudian dapat merubah pandangan masyarakat terhadap profesi pengusaha pada posisi terhormat, sehingga pada era reformasi, terutama pasca krisis ekonomi di tuntut adanya perubahan visi, dan misi organisasi. Sehingga sampai saat ini HIPMI senantiasa adaptif dengan paradigma baru yakni menjadikan Usaha Mikro Kecil-Menengah sebagai pilar utama dan lokomotif pembangunan ekonomi nasional. Hingga saat ini, jumlah anggota HIPMI di seluruh Indonesia mencapai \pm 25.000 pengusaha di Indonesia dengan mayoritas bergerak di sektor UKM.

Tujuan penelitian adalah untuk memperoleh pemahaman yang lebih baik terhadap penerimaan dan penggunaan marketplace oleh UMKM. Peneliti menggunakan Unified Theory of Acceptance and Use of The Technology (UTAUT) 2 yang akan dikolaborasikan dengan variabel perceived enjoyment. UTAUT 2 adalah salah satu model yang dapat digunakan untuk mengukur dan mempelajari penerimaan dan minat penggunaan teknologi informasi. Model UTAUT dibuat dan dikembangkan oleh (Brown, S. A., \& Venkatesh, 2005) yang mendasarkan pada kesamaan konseptual dan empiris antara delapan model penerimaan dan penggunaan teknologi sebelumnya. Menurut Venkateshet.al di tahun 2003, secara teori perspektif model UTAUT menyediakan pandangan bagaimana faktor-faktor penentu niat dan perilaku seseorang dalam menerima dan menggunakan teknologi. UTAUT 2 dikembangkan dari UTAUT yang pada awalnya menilai perilaku para pekerja dalam beradaptasi dengan teknologi yang baru digunakannya.

Hedonic Motivation yang merupakan variabel dari UTAUT yang digunakan dalam penelitian ini. Hedonik berasal dari Bahasa Yunani yaitu hedon yang artinya kesenangan atau kenikmatan. Nilai hedonic dari pencarian informasi online berhubungan dengan kesenangan dan kenikmatan dari proses pencarian online semata. Gagasan dalam penelitian (Al, 2016), (Bayashata, 2017) dan (gupta, 2017) dalam (Muhamad, 2015a) menggambarkan bahwa Hedonic Motivation berperan dalam proses pencarian informasi secara online. Menurut (Aprilia, 2017) dalam judul penelitian mengenai penerimaan pembelian online pada mahasiswa Yogyakarta terdapat pengaruh positif Hedonic Motivation terhadap perilaku pembelian online pada mahasiswa Yogyakarta. Sedangkan menurut penelitian (Santoso, 2015) melakukan penelitian mengenai minat penggunaan dan minat penggunaan mobile payment menghasilkan motivasi hedonis (Hedonic Motivations), tidak terbukti memengaruhi minat penggunaan mobile payment.

Selain itu Social Influence juga digunakan menjadi variabel dari penelitian ini. Social Influence didefinisikan sebagai tingkat dimana seorang individu menganggap orang disekitarnya seperti keluarga atau teman mengajak individu untuk menggunakan sistem baru (Venkatesh et al., 2003). Pengaruh sosial juga dianggap sama dengan subjective norm pada model penelitian. Social Influence mencerminkan pendapat dari seorang teman pengguna teknologi, kerabat, atau atasan untuk menggunakan teknologi (Venkatesh et al., 2003). Menurut penelitian(Muhamad, 2015b) dalam judul penelitian mengenai Adopsi Teknologi Internet oleh Konsumen UMKM Indonesia Untuk Belanja Online terdapat bahwa Social Influence berpengaruh positif terhadap behavioral intention. Sedangkan menurut penelitian terdahulu menguji tentang mobile banking di Yordania yang dilakukan oleh Alalwan et al., (2017) social influence tidak memiliki pengaruh terhadap minat penggunaan mobile banking.

Salah satu konstruk dari TAM yang digunakan dalam penelitian ini adalah Perceived Enjoyment. Davis mendefinisikan Perceived Enjoyment dengan: "the intrinsic reward derived through the use of the technology" (manfaat intrinsik yang didapatkan melalui penggunaan teknologi berbeda dengan motivasi ekstrinsik seperti Perceived Usefulness (persepsi manfaat) yang didasarkan pada pencapaian goals (tujuan) atau rewards (imbalan) tertentu, motivasi intrinsik mengacu pada kenyamanan melakukan kegiatan itu sendiri. 


\section{KAJIAN LITERATUR}

\section{Unified Theory of Acceptance and Use of Technology 2 (UTAUT 2)}

Unified Theory of Acceptance and Use of Technology (UTAUT) merupakan model teori yang dikembangkan oleh (Venkatesh et al., 2003) dengan menginterngrasikan delapan teori model penerimaan teknologi (technology acceptance), yaitu Theory of Reasoned Action (TRA), Technology Acceptance Model (TAM), Motivational Model (MM), Theory of Planned Behavior (TPB), A Model Combining The Technology Acceptance Model and The Theory of Planned Behavior (C-TAM-TPB), The Model of PC Utilization (MPCU), The Innovation Diffusion Theory (IDT), dan The Social Cognitive Theoary (SCT).

Model ini telah digunakan sebagai dasar teori penelitian pada beberapa perusahaan teknologi. UTAUT memiliki empat konstruk yang memengaruhi niat perilaku (behavioral intention) ke penggunaan teknologi (use a technology), empat konstruk tersebut terdiri dari ekspektasi kinerja (performance expectancy), ekspektasi usaha (effort expectancy), pengaruh sosial (social influence), dan kondisi pendukung (facilitating conditions). Ekspektasi kinerja mengacu pada kepercayaan individu bahwa teknologi yang digunakan memberikan manfaat untuk melakukan tugas pekerjaan, faktor tersebut mempengaruhi niat perilaku terhadap teknologi (Venkatesh et al., 2003). Ekspektasi usaha mengacu pada tingkat kemudahan penggunaan teknologi. Pengaruh sosial mengacu pada tingkat persepsi individu tentang seberapa banyak orang penting disekitar individu percaya akan pentingnya penggunaan teknologi. Kondisi pendukung mengacu pada sejauh mana individu percaya bahwa infrastruktur yang ada di organisasi mendukung penggunaan teknologi.

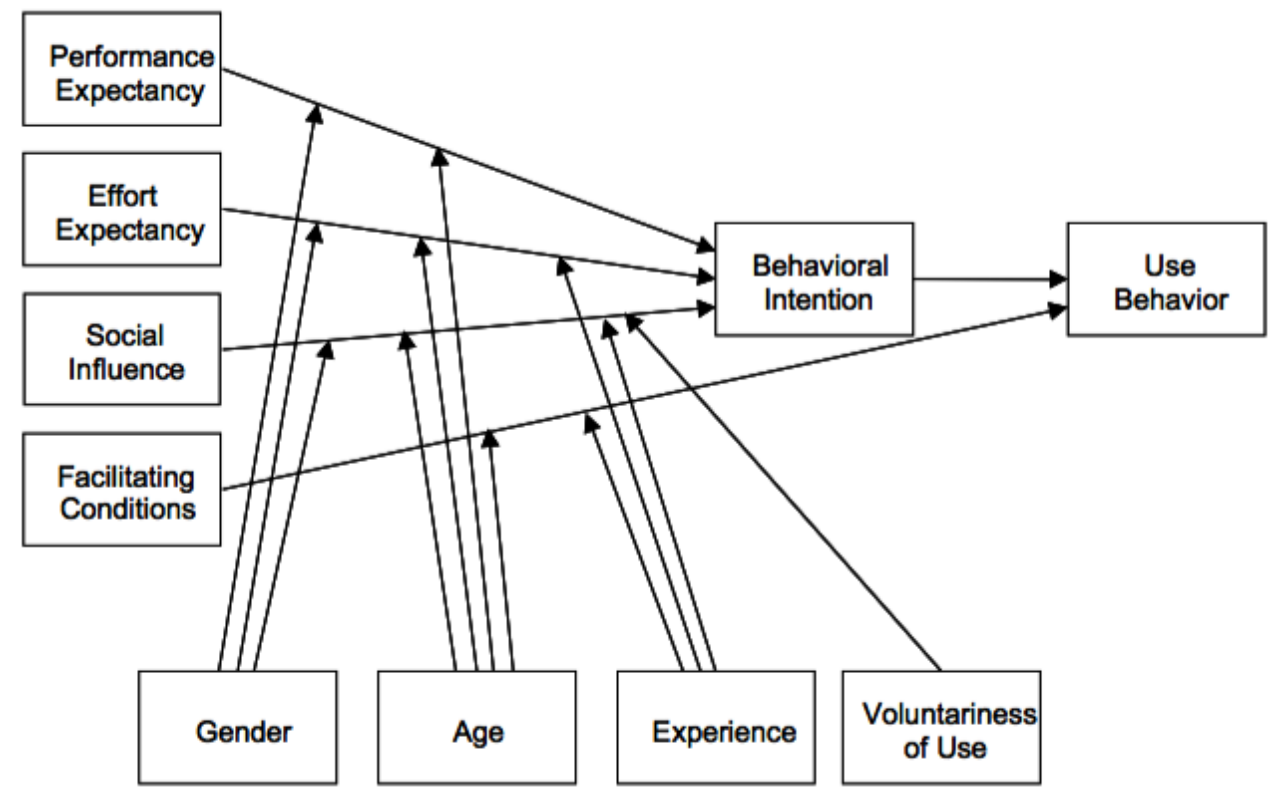

\section{Gambar 1 Kerangka Model UTAUT Sumber: (Venkatesh et al., 2003)}

Model UTAUT telah divalidasi secara empiris pada empat organisasi berbeda dari industri yang berbeda juga (Venkatesh et al., 2003). Kemudian, Chun Hua and Kai-Yu (2014) juga telah melakukan penelitian dengan lima model penerimaan teknologi dan membuktikan bahwa model UTAUT adalah model yang terbaik pada konteks teknologi. Selain itu, efisiensi predikat model UTAUT ialah $70 \%$, presentase paling tinggi dibandingkan dengan model penerimaan teknologi lainnya (DAVIS, 1989). Meskipun UTAUT adalah model yang diadopsi luas oleh industri teknologi informasi mengundang ketertarikan industri lain untuk menguji model UTAUT pada objek lain seperti perbankan, sektor kesehatan, e-commerce, dan bahkan pendidikan (Bindt005, 2015).

UTAUT telah banyak digunakan pada berbagai macam penelitian sehingga model teori ini mendapat banyak masukan dari penelitian-penelitian lain. Perluasan model teori ini 
didasarkan pada tiga alasan, yaitu setiap peneliti memiliki teknologi, populasi, dan budaya yang berbeda-beda maka mungkin memunculkan konstruk baru pada model teori ini karena perbedaan antar penelitian. Perluasan kedua ialah penambahan konstruk baru dikarenakan agar sesuai dengan konsteks tertentu yang diteliti. Selanjutnya perluasan ketiga, yaitu menambahkan prediktor eksternal yang menambahkan teori pada kerangka model UTAUT 2 (Widnyana, I. da, \& Yadnyana, 2015). Maka dari itu, pada tahun 2012, (Subhan, 2007) menyempurnakan model teori UTAUT yang bertujuan untuk memberikan kerangka model yang lebih spesifik lagi untuk menjelaskan mengenai penerimaan dan penggunaan teknologi (Venkatesh et al., 2012).

Perluasan model teori UTAUT yang baru disebut dengan UTAUT 2. Berdasarkan pada Venkatesh et al., (2012) UTAUT 2 mengenalkan tiga konstruk baru yaitu motivasi hedonis (Hedonic Motivation), nilai harga (price value), dan kebiasaan (habit). Motivasi hedonis mengacu pada tingkat kesenangan yang timbul dengan menggunakan teknologi. Nilai harga mengacu pada biaya individu untuk menggunakan atau membeli teknologi tersebut. Sementara kebiasaan dalam konteks konsumen mengacu pada otomatisitas perilaku individu agar bisa menggunakan teknologi tersebut.

Menurut Holbrook \& Hirschman (1982) dan Brown \& Venkatesh (2005) dalam Venkatesh et al., (2012) motivasi hedonis dianggap faktor kunci penting dalam perilaku konsumen dan konteks penggunaan teknologi oleh konsumen (Venkatesh et al., 2012). Nilai harga dianggap faktor penting karena konsumen juga harus menanggung biaya alat teknologi atau jasa baru yang digunakan. Sementara, faktor kebiasaan dianggap salah satu faktor yang bisa memprediksi penggunaan teknologi (Brown, S. A., \& Venkatesh, 2005).

Berdasarkan model penelitian yang diajukan oleh Venkatesh et al., (2012), model penelitian ini tidak menggunakan peran kebiasaan. Hal ini didasarkan pada kenyataan bahwa untuk menguji peran kebiasaan, pelanggan harus memiliki pengalaman yang lama dalam menggunakan suatu teknologi (Elvandari, n.d.).

1. Hedonic Motivation Terhadap Penggunaan Marketplace pada UMKM

Hedonic Motivation menggambarkan sebuah kegembiraan atau kesenangan individu dari ketertarikannya menggunakan teknologi. Venkatesh et al., (2012) mengusulkan hubungan langsung antara Hedonic Motivation dengan minat individu dalam menggunakan teknologi. Konsep dari motivasi hedonis terdiri dari beberapa intrinsik seperti kesenangan, kegembiraan, atau hiburan (Venkatesh et al., 2012). Hedonic Motivation telah dipertimbangkan sebagai prediktor penting pada penerimaan teknologi (Heijden, 2004) dan minat penggunaan teknologi (Venkatesh et al., 2012). Peneliti lain memberikan bukti kuat yang mendukung peran Hedonic Motivation dalam membentuk keputusan individu untuk mengadopsi sebuah teknologi seperti penelitian minat pengabdian mobile banking (Alalwan et al., 2017; Oliveira et al., 2016), e-learning system (Sheikh et al., 2017), plastic money (Makanyeza \& Mutambayashata, 2017). Berdasarkan uraian di atas makapeneliti merumuskan hipotesis:

H1: Hedonic Motivation memiliki pengaruh positif terhadap minat penggunaan marketplace pada UMKM di Bali.

2. Social Influence terhadap penggunaan Market Place pada UMKM

Social Influence mencerminkan pengaruh faktor lingkungan seperti saran atau pendapat dari keluarga, teman, atau kerabat untuk mengajak menggunakan teknologi. Berdasarkan penelitian pengembangan model UTAUT 2 oleh Venkatesh et al., (2003); Venkatesh et al., (2012), perbandingan beberapa model penelitian menemukan bahwa konstruk Social Influence memiliki banyak kesamaan, yaitu subjective norm, social factors, dan image. Peran Social Influence dalam keputusan teknologi sangat kompleks. Social Influence berdampak pada perilaku individu melalui tiga mekanisme, yaitu kepatuhan, internalisasi, dan identifikasi (Venkatesh et al., 2003). Menurut Hartwick dan Barki (1994) dalam Venkatesh et al., (2003), pandangan mengenai kepatuhan dalam literatur penerimaan teknologi menunjukkan adanya ketergantungan pendapat orang lain hanya signifikan pada tahap awal. Tahap awal ini dimaksudkan ketika pendapat individu relatif 
kurang dapat informasi (Thompson et al 1994; Vekatesh and Davis, 2000). Berdasarkan pada pemahaman tersebut, penelitian Venkatesh et al., (2003) menyimpulkan konstruk Social Influence merupakan prediktor kuat yang memiliki pengaruh pada keputusan individu untuk minat penggunaan sistem teknologi. Penelitian lain juga menunjukkan bahwa Social Influence berperan memengaruhi minat penggunaan teknologi seperti sistem transportasi (Madigan et al., 2016), mobile payment (Oliveira et al., 2016). Berdasarkan penelitian tersebut maka penelitian mencoba menguji kembali konstruk ini dengan merumusakan hipotesis:

$\mathrm{H} 2$ : Social Influence memiliki pengaruh positif terhadap minat penggunaan marketplace pada UMKM di Bali.

\section{Pengaruh Perceived Enjoyment}

Dalam penelitian ini, model penelitian di adopsi dari Tangke (1997) yang dikembangkan dari penelitian yang dilakukan oleh Davis et al. (1989) Yang menggunakan external variables, Perceived Usefulness (PU) dan Perceived Ease of Use (PEOU) sebagai dasar teori hubungan sebab akibat dari dua faktor yang membangun sikap (attitude) serta dengan menambahkan variabel perceived enjoyment yang diadopsi dari penelitian Al-Gahtani (1999) yaitu variabel yang memprediksikan tingkat kenyamanan yang dirasakan oleh user selama menggunakan sistem teknologi informasi dalam bekerja. Dengan demikian, dalam Penelitian AL-Gahtani dan King (1999) menambahkan variabel perceived enjoyment (persepsi kenyamanan) dalam pemanfaatan teknologi informasi. Variabel perceived enjoyment memiliki pengaruh terhadap pemanfaatan teknologi informasi melalui variabel intervening atau variabel moderasi sikap (attitude) dan perhatian perilaku (behavior intention). Berdasarkan paparan diatas maka hipotesis 3 (tiga) dinyatakan sebagai berikut:

H3: $\quad$ Perceived Enjoyment berpengaruh positif terhadap penggunaan marketplace pada UMKM yang terdaftar di HIPMI Bali.

\section{METODE}

\section{Lokasi Penelitian}

Penelitian ini dilakukan di Provinsi Bali dikarenakan Hipmi Bali saat ini tersebar disetiap Kabupaten yang ada di Bali.

\section{Populasi dan Sample}

Populasi didefinisikan sebagai wilayah generalisasi yang terdiri atas objek/subjek yang mempunyai kualitas dan karakteristik tertentu yang ditetapkan oleh peneliti untuk dipelajari dan kemudian ditarik kesimpulannya (Sugiyono, 2016). Populasi dalam penelitian ini adalah semua anggota aktif dari Hipmi Bali. Sampel adalah bagian dari jumlah dan karakteristik yang dimiliki oleh populasi tersebut (Sugiyono, 2016: 118). Metode pengambilan sampel yang digunakan dalam penelitian ini adalah metode Pourposive Sampling yaitu metode dimana peneliti menentukan beberapa kriteria untuk dijadikan sample. Dalam penelitian ini terdapat beberapa kriteria yaitu:
a. anggota aktif Hipmi Bali
b. memiliki usaha
c. pernah menjual produk di marketplace.

Jumlah sample yang diambil dalam penelitian ini menggunakan teori Hair et al (2010) dimana jumlah sample ditetapkan dengan perhitungan 5 x (dikali) jumlah indikator.

\section{Jenis Data}

Jenis data yang digunakan dalam penelitian ini adalah Data Kuantitatif. Data Kuantitatif adalah data yang berbentuk angka, atau data kualitatif yang diangkakan (Sugiyono:2013). Data yang diperoleh seperti, hasil jawaban responden pada kuisioner yang 
telah diberikan ke pengusaha dari termasuk ke dalam member hipmi bali. Jenis data yang digunakan dalam penelitian ini adalah Data Primer. Data Primer merupakan data yang diperoleh secara langsung dari objek yang diteliti. Menurut (Sugiyono: 2016) yang menyatakan bahwa Sumber Primer adalah sumber data yang langsung memberikan data kepada pengumpul data meliputi pengumpulan hasil kuisioner yang diberikan kepada pengusaha yang termasuk ke dalam anggota hipmi bali.

\section{Variabel Penelitian}

1. Hedonic Motivation merupakan motivasi kesenangan yang diperoleh dari penggunaan suatu sistem atau teknologi (Venkatesh et al.,2012). Dalam penelitiannya, Adnan (2014) menggunakan kenikmatan sebagai indikator untuk mengukur Hedonic Motivation konsumen ketika melakukan pembelian online.. Adapun indikator yang digunakan menurut Ozen dan Eginzek (2013) adalah sebagai berikut:
a. Adventure Shopping
b. Value Shopping
c. Idea Shopping
d. Social Shopping
e. Relaxation Shopping

2. Social Influence

Social Influence didefinisikan sebagai sejauh mana seorang individual mempersepsikan kepentingan yang dipercaya oleh or ang-orang lain yang akan mempengaruhi menggunakan system yang baru, Menurut Lee (2008) adapun indikator yang digunakan adalah sebagai berikut.
a. Informasi dari Teman
b. Dorongan dari Teman
c. Informasi dari Keluarga
d. Dorongan Dari keluarga
e. Peran
f. Status

3. Perceived Enjoyment

perceived enjoyment atau kenyamanan yang dirasakan dapat didefinisikan sebagai tingkat kepuasan konsumen merasa selama pembelian online di situs web tertentu, dalam hal ini kemampuan untuk membawa mereka kebahagiaan. Dalam penelitian Zaidi et al,. (2014) digunakan indikator:

b. Merasa nyaman saat berinteraksi dengan situs web

c. Merasa sangat nyaman menggunakan web untuk membeli produk yang diinginkan

d. Berpikir bahwa membeli produk dari situs web menarik

e. Belanja online merupakan salah satu pilihan untuk mengisi waktu luang

f. Menggunakan internet untuk berbelanja membuat gembira atau nyaman

4. Penggunaan Marketplace

Variabel Dependen dalam penelitian ini adalah penggunaan marketplace. Penggunaan didefinisikan sebagai kondisi nyata individu dalam menggunakan suatu produk. Penggunaan marketplace adalah sikap nyata satuan kerja dalam menggunakan marketplace.

Adapun indikator yang digunakan untuk penggunaan marketplace menurut Monika (2016) adalah:
a. Menggunakan marketplace
b. Mengakses marketplace
c. Membuka marketplace
d. Membantu dalam menggunakan marketplace 
HASIL DAN PEMBAHASAN

Distribusi Responden Berdasarkan Usia

\begin{tabular}{|c|l|c|c|}
\hline No & \multicolumn{1}{|c|}{ Usia } & Jumlah & $\begin{array}{c}\text { Persentase } \\
\%\end{array}$ \\
\hline 1 & $20-30$ tahun & 45 & 45 \\
\hline 2 & $30-40$ tahun & 51 & 51 \\
\hline 3 & $>50$ tahun & 4 & 4 \\
\hline \multicolumn{2}{|c|}{ Total } & $\mathbf{1 0 0}$ & $\mathbf{1 0 0}$ \\
\hline
\end{tabular}

Pada tabel diatas diketahui bahwa responden didominasi oleh usia 3040 tahun yaitu sebanyak 51 orang atau sebesar $51 \%$ dan paling sedikt pada usia $>50$ tahun sebanyak 4 dengan persentase $4 \%$.

1. Responden berdasarkan jenis kelamin

Distribusi Responden Berdasarkan Jenis Kelamin

\begin{tabular}{|c|l|c|c|}
\hline No & \multicolumn{1}{|c|}{$\begin{array}{c}\text { Jenis } \\
\text { Kelamin }\end{array}$} & Jumlah & $\begin{array}{c}\text { Persentase } \\
\%\end{array}$ \\
\hline 1 & Laki-laki & 63 & 63 \\
\hline 2 & Perempuan & 37 & 37 \\
\hline \multicolumn{2}{|c}{ Total } & $\mathbf{1 0 0}$ & $\mathbf{1 0 0}$ \\
\hline
\end{tabular}

Berdasarkan Tabel diatas menunjukkan bahwa responden pada penelitian ini didominasi olehlaki-laki, dimana laki-laki sebanyak 63 orang atau sebesar 63 persen dan perempuan sebanyak 37 orang atau sebesar 37 persen.

2. Responden berdasarkan Jenis Usaha

Distribusi Responden Berdasarkan Jenis Usaha

\begin{tabular}{|c|l|c|c|}
\hline No & \multicolumn{1}{|c|}{$\begin{array}{c}\text { Jenis } \\
\text { Kelamin }\end{array}$} & Jumlah & $\begin{array}{c}\text { Persentase } \\
\%\end{array}$ \\
\hline 1 & Dagang & 54 & 54 \\
\hline 2 & Jasa & 46 & 46 \\
\hline \multicolumn{2}{r|}{ Total } & $\mathbf{1 0 0}$ & $\mathbf{1 0 0}$ \\
\hline
\end{tabular}

Berdasarkan Tabel diatas menunjukkan bahwa responden pada penelitian ini didominasi oleh reponden yang memiliki usaha dagang sebanyak 54 atau sebesar 54 persen dan paling sedikit pada responden yang memiliki usaha dibidang jasa dengan jumlah 46 atau sebesar 46 persen 


\section{Hasil Analisis Statistik Deskriptif}

Deskripsi variabel penelitian menjabarkan informasi masing-masing variabel penelitian dan statistik deskriptif masing-masing variabel untuk memberikan gambaran tentang karakteristik masing-masing variabel penelitian, antara lain mean, minimum, maksimum dan standar deviasi.

\section{Hasil Statistik Deskriptif \\ Descriptive Statistics}

\begin{tabular}{|l|r|r|r|r|r|c|}
\hline & $\mathrm{N}$ & $\begin{array}{c}\text { Minimu } \\
\mathrm{m}\end{array}$ & $\begin{array}{c}\text { Maximu } \\
\mathrm{m}\end{array}$ & Mean & $\begin{array}{c}\text { Std. } \\
\text { Deviatio } \\
\mathrm{n}\end{array}$ & $\begin{array}{c}\text { Varianc } \\
\mathrm{e}\end{array}$ \\
\hline HEDONICMOTIVATION & 100 & 10.00 & 20.00 & 16.6700 & 2.95096 & 8.708 \\
SOCIALINFLUENCE & 100 & 12.00 & 24.00 & 20.3600 & 3.09617 & 9.586 \\
PERCEIVEDENJOYEDMEN & 100 & 10.00 & 20.00 & 16.7000 & 2.83378 & 8.030 \\
T & & & & & & \\
PENGGUNAANMARKETPL & 100 & 8.00 & 16.00 & 13.4500 & 2.22645 & 4.957 \\
ACE & 100 & & & & & \\
Valid N (listwise) & & & & & \\
\hline
\end{tabular}

Dari Tabel diatas dapat diuraikan deskripsi masing-masing variabel sebagai berikut:

\section{Hedonic Motivation}

Berdasarkan statistik deskriptif sesuai dengan Tabel 4.7 diperoleh nilai minimum dari Hedonic motivation sebesar 10,00 sedangkan nilai maksimum sebesar 20,00. Nilai rata-rata dari Hedonic motivation sebesar 16.6700 dan standar deviasi sebesar. 2.95096.

2. Social Influence

Berdasarkan statistik deskriptif sesuai dengan Tabel 4.7 diperoleh nilai minimum dari Social Influence sebesar 12,00. Sedangkan nilai maksimum sebesar 24,00. Nilai rata-rata dari Social Influence sebesar 20,3600 dan standar deviasi sebesar 3,09617.

\section{Perceived Enjoyment}

Berdasarkan statistik deskriptif sesuai dengan Tabel 4.7 diperoleh nilai minimum dari Social Enjoyment 10,00. Sedangkan nilai maksimum sebesar 20,00. Nilai rata-rata dari Perceived Enjoyment sebesar 16,7000 dan standar deviasi dari skala usaha sebesar 2.83378

\section{Penggunaan Marketplace}

Berdasarkan statistik deskriptif sesuai dengan Tabel 4.7 diperoleh nilai minimum dari penggunaan Marketplace sebesar 8,00. Sedangkan nilai maksimum sebesar 16,00. Nilai ratarata dari penggunaan Marketplace sebesar 13,4500 dan standar deviasi dari penggunaan Marketplace sebesar 2,22645. 


\begin{tabular}{|c|c|c|c|c|c|c|}
\hline \multicolumn{7}{|c|}{ Hasil Uji Analisis Regresi Linear Berganda } \\
\hline \multirow{2}{*}{\multicolumn{2}{|c|}{ Model }} & \multicolumn{2}{|c|}{ Unstandardized } & \multirow{2}{*}{$\begin{array}{c}\text { Standardized } \\
\text { Coefficients } \\
\text { Betta }\end{array}$} & \multirow{2}{*}{$\mathbf{T}$} & \multirow{2}{*}{ Sig } \\
\hline & & B & Std. & & & \\
\hline \multirow[t]{4}{*}{1} & (Constant) & 0,388 & 0,805 & & 0,482 & 0,631 \\
\hline & Hedonic motivation & 0,315 & 0,054 & 0,417 & 5,845 & 0,000 \\
\hline & Social influence & 0,183 & 0,053 & 0,254 & 3,428 & 0,001 \\
\hline & $\begin{array}{l}\text { Perceived } \\
\text { enjoyedment }\end{array}$ & 0,245 & 0,067 & 0,312 & 3,675 & 0,000 \\
\hline \multicolumn{2}{|c|}{$\begin{array}{l}\text { R Square }=0,750 \\
\text { Adjusted } R=0,742\end{array}$} & \multicolumn{3}{|c|}{$\begin{array}{l}F=95,812 \\
\text { Sig }=0,000\end{array}$} & & \\
\hline
\end{tabular}

Berdasarkan tabel hasil uji analisis regresi linear berganda tersebut diatas, maka persamaan regresi dalam penelitian ini adalah sebagai berikut:

$$
\begin{aligned}
& Y=0,388+0,315 X_{1}+0,183 X_{2}+0,245 X_{3}+e \\
& \text { Keterangan : }
\end{aligned}
$$

1. Koefisien konstanta sebesar 0,388 yang memiliki makna bahwa apabila variable hedonic motivation $\left(\mathrm{X}_{1}\right)$, social influence $\left(\mathrm{X}_{2}\right)$ dan perceived enjoyment $\left(\mathrm{X}_{3}\right)$ pada angka nol $(0)$ maka penggunaan marketplace $(\mathrm{Y})$ sebesar konstan yaitu 0,388

2. Nilai koefisien regresi hedonic motivation adalah sebesar 0,315 artinya setiap peningkatan pada variabel hedonic motivation dapat meningkatkan penggunaan market place. Apabila variabel hedonic motivation meningkat sebesar 1 satuan maka penggunaan market place juga akan meningkat sebesar 0,315 .

3. Nilai koefisien regresi social influence adalah sebesar 0,183 artinya setiap peningkatan pada variabel social influence dapat meningkatkan penggunaan marketplace. Apabila variabel social influence meningkat sebesar 1 satuan maka penggunaan marketplace juga akan meningkat sebesar 0,183.

4. Nilai koefisien regresi perceived enjoyment adalah sebesar 0,245 artinya setiap peningkatan pada variabel perceived enjoyment dapat meningkatkan penggunaan marketplace. Apabila variabel perceived enjoyment meningkat sebesar 1 satuan maka penggunaan marketplace juga akan meningkat sebesar 0,245.

\section{Hasil Uji Signifikansi Koefisien Regresi secara Parsial (Uji-t)}

Uji ini digunakan untuk mengetahui model regresi variabel independen $(X)$ berpengaruh terhadap variabel dependen $(Y)$. Tingkat signifikansi yang digunakan $0,05(\alpha=5 \%)$ dengan kriteria pengujian apabila signifikansi t-hitung lebih kecil dari 0,05 berarti variabel independen $(\mathrm{X})$ berpengaruh terhadap variabel dependen $(\mathrm{Y})$ dan sebaliknya apabila signifikansi t hitung lebih besar dari 0,05 berarti variabel independen $(X)$ tidak berpengaruh terhadap variabel dependen. 


\begin{tabular}{|c|c|c|c|c|c|}
\hline \multirow{3}{*}{ Model } & (Regre & si Parsial) & & & \\
\hline & \multicolumn{2}{|c|}{$\begin{array}{l}\text { Unstandardized } \\
\text { Coefficients }\end{array}$} & \multirow{2}{*}{$\begin{array}{c}\begin{array}{c}\text { Standardiz } \\
\text { ed } \\
\text { Coefficient } \\
\text { s }\end{array} \\
\text { Beta }\end{array}$} & \multirow[t]{2}{*}{$t$} & \multirow[t]{2}{*}{ Sig. } \\
\hline & $B$ & Std. Error & & & \\
\hline (Constant) & .388 & .805 & & .482 & .631 \\
\hline HedonicMotivation & .315 & .054 & .417 & 5.845 & .000 \\
\hline Social Influence & .183 & .053 & .254 & 3.428 & .001 \\
\hline Perceived Enjoyment & .245 & .067 & .312 & 3.675 & .000 \\
\hline
\end{tabular}

Berdasarkan tabel uji regresi parsial (uji t) menunjukan bahwa variabel Hedonic Motivatian, Social Influence, Perceived Enjoyment mempengaruhi Penggunaan Marketplace secara signifikan. Hal ini dapat dilihat dari nilai probabilitas signifikansi Hedonic Motivation sebesar 0,000 (sig < 0,05), Social Influence sebesar 0,001 (sig < 0,05), Perceived Enjoyment sebesar 0,000 (sig < 0,05).

\section{Pembahasan}

\section{Pengaruh Hedonic Motivation (X1) secara parsial terhadap Penggunaan Marketplace} Pada UMKM Di Bali (Y).

Pengujian signifikansi pengaruh Hedonic Motivation (X1) terhadap Penggunaan Marketplace (Y), secara parsial dilakukan dengan melakukan uji t, yaitu dengan membandingkan nilai signifikansi t dengan $\alpha(0,05)$. Berdasarkan tabel 4.13 besar nilai signifikansi t hitung variabel persepsi kegunaan dengan nilai sig $0,001<\alpha(0,05)$ yang berarti penolakan $\mathrm{H}_{0}$ sehingga $\mathrm{H}_{1}$ dapat diterima, sehingga Hedonic Motivation berpengaruh positif dan signifikan terhadap Penggunaan Marketplace. Dari hasil penelitian ini dapat diinterpretasikan bahwa pengusaha yang memiliki tingkat Hedonic Motivation yang tinggi akan memiliki tingkat Penggunaan Marketplace yang tinggi pula.

\section{Pengaruh Social Influence (X2) secara parsial terhadap Penggunaan Marketplace Pada UMKM Di Bali (Y).}

Pengujian signifikansi pengaruh Social Influence (X2) terhadap Penggunaan Marketplace (Y), secara parsial dilakukan dengan melakukan uji t, yaitu dengan membandingkan nilai signifikansi t dengan $\alpha(0,05)$. Berdasarkan tabel 4.13 nilai signifikansi t hitung variabel persepsi kemudahan penggunaan $0,012<\alpha(0,05)$ yang berarti penolakan $\mathrm{H}_{0}$ sehingga $\mathrm{H}_{2}$ dapat diterima, Sehingga Social Influence berpengaruh positif dan signifikan terhadap Penggunaan Marketplace. Dari hasil penelitian ini dapat diinterpretasikan bahwa pengusaha yang memiliki Social Influence yang tinggi akan memiliki tingkat penggunaan Marketplace yang tinggi pula.

\section{Pengaruh Perceived Enjoyment (X3) secara parsial terhadap Penggunaan Marketplace Pada UMKM Di Bali (Y).}

Pengujian signifikansi pengaruh Perceived Enjoyment (X3) terhadap Penggunaan Marketplace ( $\mathrm{Y}$ ) secara parsial dilakukan dengan melakukan uji t, yaitu dengan membandingkan nilai signifikansi t dengan $\alpha(0,05)$. Berdasarkan tabel 4.13 nilai signifikansi t hitung variabel pengetahuan akuntansi dengan nilai sig $0,014<\alpha(0,05)$ yang berarti penolakan $\mathrm{H}_{0}$ sehingga $\mathrm{H}_{3}$ diterima, Sehingga Perceived Enjoyment berpengaruh positif dan signifikan terhadap Penggunaan Marketplace. Dari hasil penelitian ini dapat diinterpretasikan 
bahwa penguasaha yang memiliki tingkat Perceived Enjoyment yang tinggi akan memiliki tingkat Penggunaan Marketplace yang tinggi pula.

\section{SIMPULAN}

\section{Simpulan}

Berdasarkan pembahasan yang telah diuraikan pada bab sebelumnya maka diperoleh simpulan sebagai berikut:

1. Hedonic motivation memiliki pengaruh yang positif dan signifikan terhadap penggunaan marketplace. Dimana hedonic motivation memiliki koefisien t sebesar 5,845 dan signifikansi sebesar 0,000 .

2. Social influence memiliki pengaruh yang positif dan signifikan terhadap penggunaan marketplace. Dimana social influence memiliki koefisien t sebesar 3,428 dan signifikansi sebesar 0,001.

3. Perceived enjoyment memiliki pengaruh yang positif dan signifikan terhadap penggunaan marketplace. Dimana perceived enjoyment memiliki koefisien t sebesar 3,675 dan signifikansi sebesar 0,000 .

\section{Saran}

1. Saran yang dapat diiberikan oleh peneliti adalah membantu pelaku UMKM dalam meningkatkan pengetahuan dan penguasaan dibidang teknologi informasi dengan cara memebrikan pelatihan-pelatihan dan membantu melakukan promosi agar nantinya produk UMKM lebih dikenal dan para pelaku UMKM diharapakan dapat melakukan kerjasama dengan berbagai pihak yang dapat mendukung penjualan melalui fasilitas elektronik

2. Bagi peneliti selanjutnya, agar dapat meneliti dan menggunakan variabel lain untuk mengetahui lebih dalam faktor-faktor lain yang tidak diteliti dalam penelitian ini yang dapat mempengaruhi pengguaan marketplace hedonic motivation, social influence dan penggunaan marketplace. Agar nantinya dapat mengetahui tindakan apa yang harus dilakukan untuk meningkatkan penggunaan marketplace.

\section{REFERENSI}

Al, olivier et. 2016. Minat Penggunaan dan Minat Penggunaan Mobil Payment Menghasilkan Motivasi Hedonis.

Aprilia. 2017. Analisis faktor-faktor yang mempengaruhi perilaku pembelian online pada mahasiswa Jogjakarta.

Bayashata, mayanyeza and M. 2017. Consumers' Acceptance and Use of Plastic Money In Harare. Zimbabwe: Application of The Unified Theory of Acceptance and Use Technology 2.

Bindt005. 2015. Pemerintah Terus Genjot Pengguna e-Commerce. Diambil kembali dari Kementrian Komunikasi dan Informatika Republik Indonesia. Retrieved from http://kominfo.go.id/index.php/content/detail/4546/Menkominfo- Pemerintah-Terus-Genjot-Pengguna-eCommerce/0/berita_satker\#.VbPoi7Oqqkp

Brown, S. A., \& Venkatesh, V. 2005. Model of Adoption and Technology in Households: A Baseline Model Test and Extension Incorporating Household Life Cycle (pp. 399-436). Retrieved from https://doi.org/10.2307/25148690

Elvandari, S. D. 2015. Penerimaan Sistem Online Shopping berdasarkan Uni ed Theory of Acceptance and Usage of Technology, 72-91.

Ghozali, I. 2013. "Aplikasi Analisis Multivariate dengan Program IBM SPSS 21".

Gupta, dogra and G. 2017. What Determines TOURIST adaption of Smartphone Apps? an Analysis BASED on The UTAUT 2 Framework. 
Muhamad, R. 2015. Adopsi Teknologi Internet oleh Komnsumen UMKM Indonesia Untuk Belanja Onlline (Studi Kasus Pada Situs Tokopedia.com 2015)..

Santoso, B. 2015. Pengaruh Perceived Usefulness, Perceived Ease Of Use, and Perceived Enjoyment Terhadap Penerimaan Teknologi Informasi.

Subhan, M. 2007. Pengaruh Variable Perceived Usefulness, Perceived Ease of Use, dan Psychological Attachment Terhadap Pemanfaatan teknologi Informasi.

Sugiyono. 2016. "Metode Penelitian Pendidikan".

Widnyana, I. da, \& Yadnyana, I. K. 2015. Implikasi Model UTAUT Dalam Menjelaskan Faktor Niat dan Penggunaan SIPKD Kabupaten Tabanan, 11(2), 515. 